\title{
CONTRIBUIÇÕES À FORMAÇÃO DE PROFESSORES DE QUÍMICA PARA ATUAÇÃO EM ESPAÇO DE EDUCAÇÃO NÃO FORMAL: QUADRO ANALÍTICO COMO FACILITADOR DA AVALIAÇÃO
}

\author{
Ariane Baffa Lourenço ${ }^{a}$, Maria Eduarda Vizotto ${ }^{\mathrm{a}}$ e Salete Linhares Queiroz ${ }^{\mathrm{a}, *,(1)}$ \\ anstituto de Química de São Carlos, Universidade de São Paulo, 13560-970 São Carlos - SP, Brasil
}

Recebido em 17/03/2021; aceito em 11/05/2021; publicado na web em 16/06/2021

\begin{abstract}
CONTRIBUTIONS TO CHEMISTRY TEACHER EDUCATION FOR ACTION IN NON-FORMAL EDUCATIONAL SETTING: ANALYTICAL FRAMEWORK AS AN EVALUATION FACILITATOR. This work presents an analytical framework focusing on the evaluation of contributions of formative actions to teaching practice. It consists of thirteen indicators, distributed into four levels, The framework was developed from analyzing participants' final assignment, who attended a Specialization Course in Teaching Methodology in Natural Sciences, offered in a non-formal education setting. Potentialities and limitations related to the teacher education framework are discussed, as well as its application in the context of teaching chemistry.
\end{abstract}

Keywords: teacher education; chemistry; analytical framework; non-formal educational settings.

\section{INTRODUÇÃO}

Aos professores de química em exercício é esperado que constantemente tenham acesso a condições de aprimoramento de competências de ensino, que incorporem estratégias contemporâneas em suas aulas, bem como assumam uma postura de pesquisador de suas ações docentes, pautados em elementos teóricos da literatura. ${ }^{1} \mathrm{~A}$ preparação desses profissionais para o atendimento a tais demandas ocorre, usualmente, em cursos de formação continuada, oferecidos em instituições de ensino formal e não formal. Em especial, a formação em espaços de educação não formal, como museus e centro de ciências, proporciona ao professor um contato mais amplo de experiências educativas, para além do ambiente escolar, de maneira a promover o entendimento sobre o potencial didático desses locais, o que pode ser refletido em sua prática. ${ }^{2}$

Embora a formação continuada de professores de química em espaços de educação não formal seja recomendada, no cenário nacional as pesquisas que envolvem essa temática podem ser consideradas como recentes e com um campo muito grande a ser explorado. Na literatura destaca-se a dissertação de Silva, ${ }^{2}$ intitulada "Formação docente \& centro de ciências: estudo sobre uma experiência de formação continuada de professores de química". Esta relata o oferecimento a professores do ensino médio de um curso, realizado no Centro de Ciências da Universidade Federal de Juiz de Fora, sobre o uso de experimentos no ensino de química, bem como analisa as contribuições e limitações dessa formação. Os resultados apontam que os professores consideraram que o desenvolvimento da formação em um centro de ciências favoreceu o acesso à infraestrutura da instituição, aos recursos materiais para o desenvolvimento de atividades experimentais e a uma assessoria científico-pedagógica e reflexiva sobre conteúdos e experimentos direcionados ao ensino médio. $\mathrm{O}$ trabalho destaca ainda a necessidade de "investigar o impacto dessas iniciativas de formação docente na prática pedagógica cotidiana das escolas e, consequentemente, no Ensino de Ciências no Brasil" (p. 204). ${ }^{2}$

Tempesta e Gomes ${ }^{3}$ também recomendam o desenvolvimento de investigações que abordem, por exemplo, se os conhecimentos adquiridos pelos professores em museus e centros de ciências são refletidos em sua prática pedagógica. Os autores destacam ainda

*e-mail: salete@iqsc.usp.br que "esse é um campo muito rico, que pode trazer muitos bons resultados e benefícios para o ensino de ciências, merecendo ser melhor explorado" (p. 99). ${ }^{3}$

É, portanto, imprescindível que os resultados atingidos sejam adequadamente analisados, de maneira que apontem as contribuições de programas de formação continuada nos quais participam os professores para o seu desenvolvimento profissional. André 4 revela que no Brasil, em geral, não há avaliação sistemática de como a formação continuada impacta o exercício do professor em sala de aula. Nessa perspectiva, o autor salienta o aspecto individualizado das mesmas: "as ações formativas são desenvolvidas sob a forma de oficinas, palestras e cursos de curta e longa duração, presenciais e a distância, voltados, em geral, para o professor, e não para a escola" (p. 43). ${ }^{4}$

Nesse contexto, advoga-se pela realização de investigação dessas ações formativas, visto que pode garantir indicativos de mudanças no trabalho do professor e justificar, assumidamente, a real necessidade de investimento em formação continuada de professores de química. É, portanto, promissor o desenvolvimento de instrumentos que possam vir a ser aplicados de modo a evidenciar as contribuições de ações formativas à prática do professor. ${ }^{5} \mathrm{O}$ presente trabalho tem como objetivo geral apresentar um Quadro Analítico direcionado a tal propósito, assim como ilustrar a sua utilização no contexto de um Curso de Especialização em Metodologia do Ensino de Ciências Naturais, oferecido em espaço de educação não formal, que contava com a participação de dois professores de química. A partir disso, é plausível a tessitura de comentários sobre as potencialidades e limitações do Quadro Analítico, construído a partir da análise de monografias de autoria dos professores, para proporcionar um melhor entendimento e avaliação de ações formativas docentes. Como elas são difundidas em diversas áreas, os resultados advindos do presente trabalho encontram aplicações em contextos que ultrapassam o da educação em química.

\section{PERCURSO METODOLÓGICO}

A etapa inicial no desenvolvimento do presente estudo consistiu na seleção de referencial teórico que subsidiasse a construção do Quadro Analítico, tendo sido eleito o Modelo de Kirkpatrick, ${ }^{6}$ desenvolvido na década de 1950. A sua escolha é baseada no fato de fornecer indicadores à compreensão, à avaliação e à contribuição 
de ações que envolvem formação em contexto organizacional em diferentes áreas do conhecimento. Os indicadores contam com quatro níveis e contemplam aspectos relacionados à reação (nível 1), à aprendizagem (nível 2), ao comportamento (nível 3) e aos resultados (nível 4) da formação para os participantes. ${ }^{6}$

Na elaboração do Quadro Analítico de Programas de Formação Continuada de Professores de Ciências, doravante denominado de QAFP, foram assumidos os mesmos quatro níveis do Modelo de Kirkpatrick. ${ }^{6}$ Em contraponto, os indicadores para cada nível, com respectivas definições e exemplos, foram elaborados a partir da análise de monografias de conclusão do referido Curso de Especialização. A pertinência da análise das monografias, tendo em vista o propósito almejado, reside no fato delas trazerem em seu bojo excertos autorais que remetem a cada um dos aspectos associados aos referidos níveis que, uma vez reunidos e analisados, conduziram à elaboração dos indicadores. A seguir é descrito o contexto de produção das monografias e o procedimento de análise ao qual foram submetidas para o alcance dos indicadores.

\section{Contexto de produção das monografias}

As monografias foram produzidas no Curso de Especialização em Metodologia do Ensino de Ciências Naturais, oferecido na modalidade presencial, pelo Centro de Divulgação Científica e Cultural da Universidade de São Paulo (CDCC/USP), que tem participação expressiva em atividades relacionadas ao ensino e à extensão na cidade de São Carlos e região e vem desenvolvendo, ao longo de décadas, iniciativas visando à formação de professores na área de ciências naturais. ${ }^{7} \mathrm{O}$ Curso foi desenvolvido a partir de uma estrutura básica envolvendo uma carga horária de 400 horas, distribuídas ao longo de 19 meses, das quais 360 h são referentes à carga horária de aulas teóricas em sala de aula e $40 \mathrm{~h}$ destinadas ao desenvolvimento de uma monografia ao final do curso.

O Curso almejou o oferecimento de especialização na área de educação em ciências a professores da educação básica que ministram disciplinas de ciências, física, química e biologia. A constituição de professores transformadores da escola foi buscada, tendo sido privilegiada a sua vivência e interação com metodologias ativas de ensino e aprendizagem.

As disciplinas foram ministradas em encontros presenciais, majoritariamente por docentes da USP, realizadas aos sábados e em semanas condensadas durante o período de férias dos professores. O conteúdo ministrado abarcou questões contemporâneas que permeiam o ensino de ciências, como o letramento midiático, a argumentação na educação científica, o desenvolvimento de atividades de experimentação de caráter investigativo, a articulação da educação não formal, educação ambiental no ensino de ciências, entre outras.

Para a redação das monografias os professores selecionaram um tema discutido nas disciplinas e a partir dele desenvolveram uma pesquisa, que poderia, ou não, estar relacionada a uma prática executada em contexto de sala de aula. Para esse processo cada professor contou com um orientador, docente do Curso, e, uma vez finalizada, a monografia foi apresentada a uma banca examinadora.

\section{Coleta e análise de dados}

No que diz respeito à coleta de dados, o CDCC cedeu as monografias no formato digital desenvolvidas pelos professores. Cabe esclarecer que todos eles assinaram Termo de Consentimento Livre e Esclarecido, no qual consta autorização para uso das monografias para fins de pesquisa acadêmica.

Foram produzidas treze monografias que abordaram temáticas relacionadas às disciplinas ministradas, sendo que oito envolviam investigações realizadas pelos professores em contexto de sala de aula. Foi desse montante que selecionamos previamente o material para análise e criação do QAFP. Esse recorte foi necessário, pois, como o impacto da formação no desenvolvimento profissional dos professores era alvo de análise, existia a necessidade de se contar com excertos autorais relacionados com suas atuações no contexto escolar. Das monografias com essas características, duas de química, duas de biologia e duas de ciências tiveram os seus dados tratados, as quais foram nomeadas de M1 a M6.

A organização do material foi realizada, inicialmente, considerando a estrutura usual das monografias: I) Partes Pré-textuais: a) Capa, b) Dedicatória, c) Agradecimentos, d) Resumo, e) Abstract; f) Listas; g) Sumário; II) Partes Textuais: h) Introdução, i) Objetivos, j) Referenciais Teóricos, 1) Metodologia, m) Resultados e Discussão, n) Considerações Finais, o) Referências Bibliográficas.

O material de estudo foi organizado de modo a que se considerasse na etapa de tratamento de dados apenas as seções das monografias redigidas em língua portuguesa e potencialmente capazes de apresentar indícios de autoria na perspectiva proposta por Possenti. ${ }^{8}$ Assim sendo, foram excluídas: Capa, Dedicatória, Listas, Sumário, Abstract, Introdução, Referenciais Teóricos e Referências Bibliográficas. Cabe esclarecimento sobre a exclusão das seções Introdução e Referencias Teóricos. Elas foram excluídas pois não apresentavam de maneira dominante agenciamento de vozes no texto, atreladas a um aumento na densidade do contexto, ou indicativos claros de que o professor tomou distanciamento em relação ao próprio texto, características que percebemos com mais clareza nas demais seções.

A título de exemplo, é apresentado a seguir excerto extraído da seção Introdução de uma das monografias, na qual não se verificam indícios de autoria, na perspectiva de Possenti, ${ }^{8}$ uma vez que as colocações do professor autor da monografia configuram-se como uma repetição do que já foi dito por outros autores. Em suma, nas seções Introdução e Referenciais Teóricos, muito frequentemente, ainda que se enunciem outros autores, notados pelos recursos de citação direta e indireta, não foram apresentados elementos pelo professor, de modo a trazer densidade à informação indicada.

\begin{abstract}
"De acordo com Carvalho e colaboradores, 'a atividade deve estar acompanhada de situações problematizadoras, questionadoras, dialogo, envolvendo, portanto, a resolução de problemas e levando à introdução de conceitos' (Carvalho et al., 1999: 42)". "Ainda, segundo os autores, a resolução de um problema pela experimentação deve envolver também reflexões, relatos, discussões, ponderações e explicações, processos típicos de uma investigação científica".
\end{abstract}

Em contraponto, indícios de autoria são verificados nas demais seções consideradas para análise, como ilustrado nos excertos, a seguir, oriundos da seção Considerações Finais de uma das monografias, no qual o professor assume um posicionamento, contrapondo os seus dados a resultados de avaliações institucionais.

"Por outro lado, os resultados das avaliações institucionais, como o SARESP, apontam para a necessidade de uma reformulação total do ensino médio".

"Assim, o ensino por experimentação e investigação, pode ser uma poderosa arma para reverter esse quadro de calamidade, que o ensino médio se encontra".

Uma vez realizada a referida exclusão, foram organizados os dados para tratamento. Para tanto, inicialmente, cada seção do texto, objeto de estudo, foi recortada em unidades de registro (UR), 
consideradas como sendo cada frase do documento. Em seguida, as UR que apresentavam indícios de autoria compuseram as Unidades de Análise (UA). Na sequência, cada UA foi classificada, quando pertinente, nos quatro níveis de avaliação propostos no Modelo de Kirkpatrick. ${ }^{6}$ Esse processo foi executado integralmente pela primeira e segunda autora do presente manuscrito, de modo a alcançar um consenso nas classificações e elevar a confiabilidade dos resultados.

Uma vez concluída esta análise preliminar, as UA reunidas em cada nível foram submetidas a uma análise de conteúdo proporcionando a elaboração de indicadores, o que resultou na construção do QAFP voltado especificamente à programas de formação continuada. Ele se encontra descrito na próxima seção e foi aplicado para análise das duas monografias da área de química.

\section{QUADRO ANALÍTICO DE PROGRAMAS DE FORMAÇÃO CONTINUADA DE PROFESSORES DE CIÊNCIAS (QAFP)}

Um quadro analítico possibilita o entendimento de um fenômeno em estudo. ${ }^{9}$ Nessa perspectiva, esta investigação permitiu a construção do QAFP, no qual se encontram, sequencialmente, os níveis de avaliação, os indicadores, suas definições e exemplos extraídos das monografias. Após a descrição de cada um desses elementos, o Quadro 1 é apresentado, de modo a sintetizar as informações mencionadas.

\section{Nível 1: Reação}

O nível de reação considera a extensão na qual os participantes julgam a formação satisfatória, favorável, envolvente e relevante para seu trabalho e desenvolvimento profissional. ${ }^{6}$ Tais elementos podem ser expressos quando se avalia a satisfação do professor quanto à formação continuada oferecida, aspectos expressos no QAFP pelos indicadores: Satisfação do professor quanto à vivência com os pares durante a formação; Satisfação do professor quanto à infraestrutura da instituição onde a formação foi realizada; Satisfação do professor quanto à atuação dos docentes da formação.

$\mathrm{O}$ indicador Satisfação do professor quanto à vivência com os pares durante a formação designa colocações do professor que expressam benefícios, tais como conhecimentos, habilidades entre outros, decorrente da interação com os colegas, na formação continuada. Esse indicador está exemplificado no Quadro 1 (Ex. 1a), em que o professor agradece aos seus colegas por proporcionarem um ambiente mútuo de aprendizagem durante a formação.

$\mathrm{O}$ indicador Satisfação do professor quanto à infraestrutura da instituição onde a formação foi realizada refere-se às colocações em que o professor expressa sua satisfação quanto ao espaço físico em que a formação foi desenvolvida. No caso de formações ocorridas em espaços não formais de aprendizagem, a satisfação, além de envolver a estrutura da sala de aula, pode incluir, por exemplo, salas de exposições, trilhas interpretativas, jardins temáticos etc. Esse indicador está exemplificado no Quadro 1 (Ex. 1b), em que o professor agradece ao CDCC pelo suporte e infraestrutura oferecidos.

O indicador Satisfação do professor quanto à atuação dos docentes formadores envolve afirmações que expressam contentamento com os docentes/orientadores que atuaram na formação. Esse contentamento pode ser devido à organização e escolha das atividades e metodologias empregadas na formação, bem como à atuação que tiveram como orientadores das monografias. Tal indicador pode ser observado no Quadro 1 (Ex. 1c), em que o professor agradece aos docentes formadores pela aprendizagem proporcionada, não somente de conceitos vinculados à área de conhecimento, como de outros aspectos fundamentais à formação profissional.

\section{Nível 2: Aprendizagem}

O nível de aprendizagem avalia a extensão com que os participantes adquirem conhecimentos e habilidades, a partir da sua participação na formação. ${ }^{6}$ Nesse contexto, são os seguintes os indicadores do nível aprendizagem direcionados à formação continuada de professores: Habilidade do professor em relacionar conteúdos teóricos abordados na formação a planejamento de práticas docentes; Habilidade do professor em utilizar instrumentos de coleta de dados da prática docente; Habilidade do professor em tratar os dados resultantes da prática docente; Habilidade do professor em analisar elou discutir os resultados da prática docente com base em conteúdos teóricos; Habilidade do professor em concluir sobre os resultados provenientes da prática docente.

Os indicadores para esse nível são apresentados em uma ordem sequencial de complexidade no QAFP e possuem elementos da natureza da construção do conhecimento científico. Nesse processo, o indicador relacionado ao planejamento da prática docente estaria em primeira ação, seguido da coleta e tratamento dos dados, sendo apresentada na sequência a análise e discussão dos resultados, finalizando na conclusão da pesquisa.

Explorando cada indicador do nível 2, tem-se que Habilidade do professor em relacionar conteúdos abordados na formação a planejamento de práticas docente ocorre quando este vale-se de conteúdos teóricos da área de Educação para planejar sua prática docente. Para verificar esse indicador é fundamental que o pesquisador que está avaliando a formação tenha conhecimento dos conteúdos nela abordados. Tal indicador encontra-se exemplificado no Quadro 1 (Ex. 2a), em que o professor coloca que o objetivo de sua pesquisa, desenvolvida em sala de aula e que resultou em sua monografia, foi estimular a prática argumentativa em suas aulas por meio da ferramenta blog. Nesse exemplo observam-se dois aspectos abordados no Curso de Especialização: argumentação e tecnologias da informação e comunicação no ensino de ciências.

$\mathrm{O}$ indicador Habilidade do professor em utilizar instrumentos de coleta de dados da prática docente é observado quando ele lança mão de instrumentos específicos da área de Educação, abordados direta ou indiretamente na formação, para a coleta de dados provenientes de sua pesquisa em sala de aula. Podem compor esses instrumentos: entrevistas, questionários, diário de bordo, gravações em áudio e vídeo, documentos de autoria dos alunos, entre outros. Tal procedimento é verificado no Quadro 1 (Ex. 2b), em que o professor descreve o uso de questionário em escala Likert para coletar os dados da sua própria pesquisa junto aos alunos.

$\mathrm{O}$ indicador Habilidade do professor em tratar os dados resultantes da prática docente ocorre quando este procede a um tratamento do material, o qual foi coletado por meio de instrumentos de coleta de dados. O indicador abarca duas vertentes: na primeira, o professor, de posse dos dados, faz um recorte selecionando aqueles que serão objetos de estudo da sua pesquisa; na segunda vertente, o professor faz uso de modelos teóricos discutidos na formação para tratar os dados. Esse último procedimento é exemplificado no Quadro 1 (Ex. 2c), na colocação em que o professor descreve o uso de dois modelos teóricos a serem empregados para analisar a estrutura e natureza dos argumentos produzidos pelos estudantes durante as atividades desenvolvidas em sua pesquisa em contexto de sala de aula.

$\mathrm{O}$ indicador Habilidade do professor em analisar elou discutir os resultados da prática docente com base em conteúdos teóricos ocorre quando ele discute seus dados, podendo inclusive apresentar elementos da literatura da área que corroboram ou destoam de seus resultados. Exemplo dessa perspectiva pode ser observado no Quadro 1 (Ex. 2d), quando o professor indica o uso do modelo de 
Análise de Argumentação Aplicável a Processos de Resolução de Questões Sócio-científicas para discutir seus resultados, quanto à promoção da argumentação em suas aulas.

$\mathrm{O}$ indicador Habilidade do professor em concluir sobre os resultados provenientes da prática docente ocorre quando ele apresenta conclusões de sua pesquisa, podendo inclusive manifestar implicações dela para a área. Tal aspecto pode ser observado no Quadro 1 (Ex. 2e), em que o professor conclui que logrou promover a argumentação dos alunos a partir de atividades pautadas no uso de blog. Esclarecemos que as UA, para serem enquadradas nesse indicador e diferenciadas do indicador de análise e discussão, precisam possuir uma estrutura de frase que direciona às considerações finais em relação ao trabalho, à recapitulação dos resultados, à retomada dos objetivos com respostas aos mesmos, às implicações da pesquisa à área de estudo e sugestões de trabalhos futuros.

\section{Nível 3: Comportamento}

O nível de comportamento considera a extensão na qual os participantes aplicam o que aprenderam na formação no seu ambiente de trabalho. ${ }^{6}$ Para esse nível são os seguintes os indicadores direcionados à formação continuada de professores: Implementação por parte do professor de práticas docentes pautadas em elementos da formação e Adaptação por parte do professor do planejamento inicial de práticas docentes pautadas em elementos da formação. $\mathrm{O}$ indicador Implementação por parte do professor de práticas docentes pautadas em elementos da formação relaciona-se às atividades aplicadas em sala de aula, tendo como base os conceitos abordados na formação. Ele está exemplificado no Quadro 1 (Ex. 3a), em que o professor descreve a implementação das atividades desenvolvidas em suas aulas, após participar da formação.

$\mathrm{O}$ indicador Adaptação por parte do professor do planejamento inicial de práticas docentes pautadas em elementos da formação reflete adaptações realizadas pelo professor sobre situações imprevistas em sala de aula, que contribuíram para a tomada de decisões durante a sua prática e consequências dela decorrentes. A verificação do indicador dá-se quando o professor apresenta claramente que alterou sua prática no momento em que estava em contexto de sala de aula, ou quando reflete sobre algum episódio vivenciado e altera para a próxima aula seu planejamento. Exemplo desse indicador pode ser observado no Quadro 1 (Ex. 3b), em que o professor relata que alterou o curso da aula, pois o tempo planejado para as ações propostas foi insuficiente.

\section{Nível 4: Resultados}

O nível 4 compreende os resultados decorrentes da aplicação da aprendizagem da formação no ambiente de trabalho, tendo em consideração os objetivos da organização em que o participante atua. ${ }^{6}$ Foram os seguintes os indicadores identificados para esse nível: Conhecimentos e habilidades adquiridos pelos estudantes a partir da prática do professor; Motivação elou satisfação demonstrada pelos estudantes consoante à prática do professor; Impacto da performance do professor no ambiente escolar, após participar da formação. $\mathrm{O}$ indicador Conhecimentos e habilidades adquiridos pelos estudantes a partir da prática do professor ocorre quando são feitas afirmações que consistem em indícios de que as atividades que o professor propôs e que foram desenvolvidas pelos estudantes levaram à aquisição de conhecimentos e habilidades. Essas afirmações podem ser, inclusive, colocadas em forma da transcrição de depoimentos colhidos junto aos estudantes. O indicador está exemplificado no Quadro 1 (Ex. 4a), em que o professor relata que, ao questionar os estudantes sobre os benefícios das atividades desenvolvidas, teve como retorno que a maioria considera que entendeu melhor o conteúdo em estudo quando foi feito uso do método de estudo de caso, o qual foi discutido na formação.

$\mathrm{O}$ indicador Motivação elou satisfação demonstrada pelos estudantes consoante a prática do professor é revelado quando ele aponta que os estudantes, ao participarem das atividades, sentiramse motivados e satisfeitos. Tal indicador é observado no Quadro 1 (Ex. 4b), em que o professor menciona que os alunos consideraram que o uso do método de estudo de caso e do método de cooperativo de aprendizagem jigsaw tornaram a aula mais divertida e menos cansativa, favorecendo sua motivação na participação.

O outro indicador desse nível, Impacto da performance do professor no ambiente escolar, após participar da formação, envolve afirmações de que a formação realizada trouxe benefícios de natureza pedagógica a sua prática docente. Tal aspecto pode ser observado no Quadro 1 (Ex. 4c), quando é relatado que participar do Curso de Especialização possibilitou tal benefício, a partir da diversificação das aulas.

O Quadro 1, conforme mencionado anteriormente, ilustra os níveis de avaliação, os indicadores, suas definições e exemplos extraídos das referidas monografias.

\section{APLICAÇÃO DO QAFP: MONOGRAFIAS SOBRE O ENSINO DE QUÍMICA EM DESTAQUE}

Uma vez construído o QAFP, analisamos as monografias sobre o ensino de química, doravante denominadas de M1 e M2. M1 está baseada nos resultados do professor 1 (P1), ao abordar o assunto agrotóxicos, na construção de blogs por alunos do terceiro ano do ensino médio (EM). A M2 relata os resultados do professor 2 (P2), ao abordar o tema chuva, a partir da implementação de uma sequência didática investigativa a alunos do segundo ano do EM. O Quadro 2 ilustra os títulos das monografias, os assuntos abordados e a quantidade de UA presente em cada uma delas.

A discussão referente aos níveis do QAFP consta a seguir, e foi realizada a partir do estabelecimento de relações entre o observado nas monografias e os respectivos indicadores de cada nível, cabendo destacar que as duas possuem número próximo de UA, 149 (M1) e 137 (M2). Destaca-se que para uma mesma UA pode ter sido identificado mais de um indicador proveniente dos diferentes níveis.

\section{Nível 1: Reação}

Todos os indicadores do nível reação foram localizados no conjunto das duas monografias (Quadro 3). As UA contempladas nesse nível foram localizadas, em quase sua totalidade, na seção Agradecimentos, que contava, em M1, com apenas 3 UA e em M2 com 5 UA, a exceção foi 1 UA encontrada na seção de Considerações Finais da M2.

A localização das UA, quase que unicamente na seção de Agradecimentos, não é surpreendente, visto que o nível 1 envolve a apresentação de elementos que estão relacionados às percepções do professor frente à formação recebida. Esses, em uma monografia, são geralmente colocados na referida seção, que tende a ocupar pouca extensão em um documento científico. Pautado nesse cenário, era também esperado que a quantidade de ocorrência de cada indicador fosse pequena, considerando o montante total de UA na seção de Agradecimentos de cada monografia, bastante restrito.

Discorrendo sobre cada um dos indicadores, tem-se que Satisfação do professor quanto à vivência com os pares durante a formação foi observado apenas em M2, assim como o indicador Satisfação do professor quanto à infraestrutura da instituição 
Quadro 1. Quadro Analítico de Programas de Formação Continuada de Professores de Ciências, baseado nos níveis de avaliação propostos no Modelo de Kirkpatrick $^{6}$

\begin{tabular}{|c|c|c|c|}
\hline $\begin{array}{l}\text { Níveis de } \\
\text { Avaliação }\end{array}$ & Indicadores & Definições & Exemplos \\
\hline \multirow{3}{*}{ 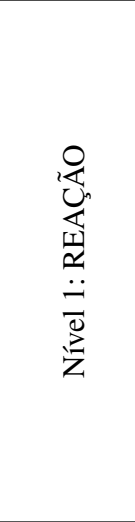 } & $\begin{array}{l}\text { Satisfação do professor } \\
\text { quanto à vivência com os } \\
\text { pares durante a formação. }\end{array}$ & $\begin{array}{l}\text { Afirmação do professor que } \\
\text { apresenta sua satisfação } \\
\text { frente à vivência com os } \\
\text { pares durante a formação. }\end{array}$ & $\begin{array}{l}\text { Às colegas de curso e agora amigas ... pelo aprendizado mútuo em } \\
\text { nossas longas jornadas de aulas. (Ex. 1a) }\end{array}$ \\
\hline & $\begin{array}{l}\text { Satisfação do professor } \\
\text { quanto à infraestrutura da } \\
\text { instituição onde a forma- } \\
\text { ção foi realizada. }\end{array}$ & $\begin{array}{l}\text { Afirmação do professor } \\
\text { quanto à satisfação frente } \\
\text { à infraestrutura da institu- } \\
\text { ição onde a formação foi } \\
\text { realizada. }\end{array}$ & $\begin{array}{l}\text { Ao Centro de Divulgação Científica e Cultural - CDCC-da Univer- } \\
\text { sidade de São Paulo em São Carlos, pelo suporte e infraestrutura } \\
\text { oferecidos. (Ex. 1b) }\end{array}$ \\
\hline & $\begin{array}{l}\text { Satisfação do professor } \\
\text { quanto à atuação dos do- } \\
\text { centes formadores. }\end{array}$ & $\begin{array}{l}\text { Afirmação do professor } \\
\text { quanto à satisfação frente } \\
\text { à atuação dos docentes } \\
\text { formadores. }\end{array}$ & $\begin{array}{l}\text { Agradeço a todos os professores por proporcionarem o conhecimento } \\
\text { não apenas racional, mas a manifestação de caráter e afetividade } \\
\text { da educação no processo de formaçâo profissional, não somente por } \\
\text { terem ensinado, mas por ter-nos feito aprender. (Ex. 1c) }\end{array}$ \\
\hline \multirow{5}{*}{ 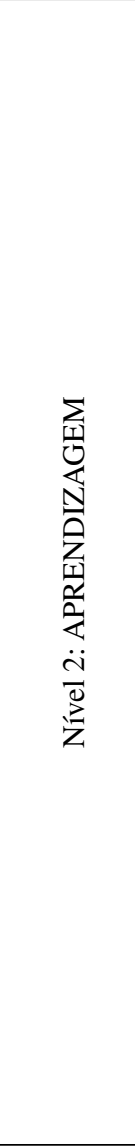 } & $\begin{array}{l}\text { Habilidade do professor } \\
\text { em relacionar conteúdos } \\
\text { teóricos abordados na } \\
\text { formação a planejamento } \\
\text { de práticas docentes. }\end{array}$ & $\begin{array}{l}\text { Afirmação do professor } \\
\text { que relaciona conteúdos } \\
\text { teóricos ao planejamento } \\
\text { de práticas docentes. }\end{array}$ & $\begin{array}{l}\text { Este trabalho tem como objetivo desenvolver e estimular a prática } \\
\text { argumentativa em aulas de química no ensino médio, a partir do uso } \\
\text { de blogs. (Ex. } 2 \mathrm{a})\end{array}$ \\
\hline & $\begin{array}{l}\text { Habilidade do professor } \\
\text { em utilizar instrumentos } \\
\text { de coleta de dados da } \\
\text { prática docente. }\end{array}$ & $\begin{array}{l}\text { Afirmação do professor } \\
\text { que remete à utilização de } \\
\text { instrumentos para coletar } \\
\text { dados que possibilitam a } \\
\text { investigação da sua prática } \\
\text { docente. }\end{array}$ & $\begin{array}{l}\text { Para a coleta de dados quantitativos neste trabalho, eu propus que os } \\
\text { alunos respondessem individualmente um questionário sobre as per- } \\
\text { cepções destes ao realizar as atividades. O questionário foi expresso } \\
\text { em escala Likert de cinco pontos (concordo fortemente }(C F) \text {, concordo } \\
(C) \text {, indeciso }(I) \text {, discordo }(D) \text {, discordo fortemente }(D F) \text { ). (Ex. 2b) }\end{array}$ \\
\hline & $\begin{array}{l}\text { Habilidade do professor } \\
\text { em tratar os dados resul- } \\
\text { tantes da prática docente. }\end{array}$ & $\begin{array}{l}\text { Afirmação do professor que } \\
\text { remete ao tratamento dos } \\
\text { dados que possibilitam a } \\
\text { investigação da sua prática } \\
\text { docente. }\end{array}$ & $\begin{array}{l}\text { A estrutura dos argumentos apresentados nos blogs foi analisada de } \\
\text { acordo com o Modelo de Toulmin (2001) e com o Modelo de Análise } \\
\text { de Argumentação Aplicável a Processos de Resolução de Questões } \\
\text { Socio-científicas (SÁ, 2010), descritos sucintamente no tópico a } \\
\text { seguir. (Ex. 2c) }\end{array}$ \\
\hline & $\begin{array}{l}\text { Habilidade do professor } \\
\text { em analisar e/ou discutir } \\
\text { os resultados da prática } \\
\text { docente com base em } \\
\text { conteúdos teóricos. }\end{array}$ & $\begin{array}{l}\text { Afirmação do professor } \\
\text { que remete à análise e/ou } \\
\text { discussão dos dados resul- } \\
\text { tantes, da implementação } \\
\text { da atividade, à luz de fun- } \\
\text { damentos teóricos. }\end{array}$ & $\begin{array}{l}\text { No que diz respeito ao critério ambiental, a aluna menciona a possi- } \\
\text { bilidade de morte das abelhas devido ao uso dos agrotóxicos e sugere } \\
\text { a substituição dos mesmos por pesticidas naturais e a plantação } \\
\text { de horta caseira para diminuir a compra dos agrotóxicos. (Ex. } 2 \mathrm{~d} \text { ) }\end{array}$ \\
\hline & $\begin{array}{l}\text { Habilidade do professor } \\
\text { em concluir sobre os re- } \\
\text { sultados provenientes da } \\
\text { prática docente. }\end{array}$ & $\begin{array}{l}\text { Afirmação do professor que } \\
\text { apresenta sua conclusão } \\
\text { frente aos dados obtidos } \\
\text { após tratamento e análise/ } \\
\text { discussão, podendo inclu- } \\
\text { sive apresentar implicações } \\
\text { da pesquisa à área. } \\
\end{array}$ & $\begin{array}{l}\text { Podemos concluir que o objetivo do trabalho, que era, principalmente, } \\
\text { desenvolver e estimular a prática argumentativa, por meio de uma } \\
\text { intervenção didática baseada no uso dos blogs, foi alcançado. (Ex. 2e) }\end{array}$ \\
\hline \multirow{2}{*}{ 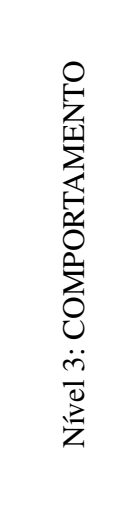 } & $\begin{array}{l}\text { Implementação por parte } \\
\text { do professor de práticas } \\
\text { docentes pautadas em } \\
\text { elementos da formação. }\end{array}$ & $\begin{array}{l}\text { Afirmação do professor } \\
\text { que remete à aplicação de } \\
\text { atividades em ambientes de } \\
\text { ensino tendo como base os } \\
\text { conhecimentos abordados } \\
\text { na formação. }\end{array}$ & $\begin{array}{l}\text { Ainda na primeira etapa, o esquema proposto por Piassi e Pietrocola } \\
\text { (2007), disponível no trabalho de Fatareli et al. (2014) e ilustrado na } \\
\text { Figura 3, foi apresentado aos alunos para que pudessem compreender } \\
\text { melhor como proceder em um debate e definir maneiras sobre como } \\
\text { deveriam iniciar suas argumentações a partir do tema que foi definido } \\
\text { para cada grupo. (Ex. 3a) }\end{array}$ \\
\hline & $\begin{array}{l}\text { Adaptação por parte do } \\
\text { professor do planeja- } \\
\text { mento inicial de práticas } \\
\text { docentes pautadas em } \\
\text { elementos da formação. }\end{array}$ & $\begin{array}{l}\text { Afirmação do professor } \\
\text { que remete a adaptações } \\
\text { feitas para enfrentamento } \\
\text { de situações imprevistas } \\
\text { ao implementar sua prática, } \\
\text { pautadas em elementos da } \\
\text { formação. }\end{array}$ & $\begin{array}{l}\text { O tempo de duas aulas de } 50 \text { minutos não foi suficiente para posta- } \\
\text { rem e argumentarem sobre seu tema, ficando decidido que eles iriam } \\
\text { terminar em suas casas. (Ex. } 3 \mathrm{~b} \text { ) }\end{array}$ \\
\hline
\end{tabular}


Quadro 1. Quadro Analítico de Programas de Formação Continuada de Professores de Ciências, baseado nos níveis de avaliação propostos no Modelo de Kirkpatrick $^{6}$ (cont.)

\begin{tabular}{|c|c|c|c|}
\hline \multirow{3}{*}{ 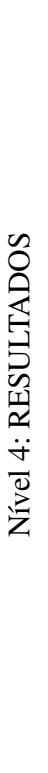 } & $\begin{array}{l}\text { Conhecimentos e habili- } \\
\text { dades adquiridos pelos es- } \\
\text { tudantes a partir da prática } \\
\text { do professor. }\end{array}$ & $\begin{array}{l}\text { Afirmação do professor } \\
\text { que aponta para indícios de } \\
\text { aprendizagem dos seus es- } \\
\text { tudantes perante atividades } \\
\text { didáticas implementadas, } \\
\text { verificada por meio de in- } \\
\text { dicações explícitas de ações } \\
\text { realizadas pelos mesmos. }\end{array}$ & $\begin{array}{l}\text { Os resultados foram extremamente relevantes com relação à afirma- } \\
\text { ção contida na questão } 1 \text {, uma vez que a maioria dos alunos (...), } \\
\text { afirmou que a atividade de investigação proposta no caso os ajudou a } \\
\text { entender melhor os temas trabalhados nas aulas de ciências. (Ex. } 4 \text { a) }\end{array}$ \\
\hline & $\begin{array}{l}\text { Motivação e/ou satisfação } \\
\text { demonstrada pelos estu- } \\
\text { dantes consoante à prática } \\
\text { do professor. }\end{array}$ & $\begin{array}{l}\text { Afirmação do professor } \\
\text { que sinaliza motivação e/ou } \\
\text { satisfação dos estudantes ao } \\
\text { desenvolverem atividades } \\
\text { didáticas implementadas } \\
\text { pautadas em elementos da } \\
\text { formação. } \\
\end{array}$ & $\begin{array}{l}\text { As respostas dadas à afirmação } 10 \text { mostram que } 100 \% \text { dos alunos } \\
\text { concordam (somatória das respostas CF e C) que o uso de diferentes } \\
\text { métodos de ensino (como estudos de caso e formato de aula jigsaw) } \\
\text { tornam as aulas mais divertidas e menos cansativas, enfatizando a } \\
\text { importância no sentido de aumentar a motivação dos alunos em sala } \\
\text { de aula, favorecendo assim as habilidades interpessoais e cognitivas. } \\
\text { (Ex. } 4 \mathrm{~b} \text { ) }\end{array}$ \\
\hline & $\begin{array}{l}\text { Impacto da performance } \\
\text { do professor no ambiente } \\
\text { escolar, após participar da } \\
\text { formação. }\end{array}$ & $\begin{array}{l}\text { Afirmação do professor } \\
\text { indicando que sua per- } \\
\text { formance trouxe efeitos } \\
\text { de cunho pedagógico ao } \\
\text { ambiente escolar. }\end{array}$ & $\begin{array}{l}\text { Através do curso de especialização em ensino de Ciências, realizado } \\
\text { pelo CDCC-Centro de Divulgação Cultural e Científica de São } \\
\text { Carlos, tive a oportunidade em conhecer "novas" metodologias de } \\
\text { ensino e diversificar minha prática. (Ex. } 4 \mathrm{c} \text { ) }\end{array}$ \\
\hline
\end{tabular}

Quadro 2. Caracterização das monografias direcionadas ao ensino de química

\begin{tabular}{|c|c|c|c|}
\hline & Título da monografia & Assunto abordado & Quantidade UA \\
\hline M1 & Uso de blogs na promoção da argumentação no ensino médio de química & Agrotóxicos & 149 \\
\hline M2 & As concepções dos alunos da $2^{\mathrm{a}}$ série do ensino médio sobre o processo da chuva & Chuva & 137 \\
\hline
\end{tabular}

Quadro 3. Quantidade de UA das monografias dos professores de química relacionadas ao nível 1

\begin{tabular}{|l|c|c|}
\hline \multirow{2}{*}{} & \multicolumn{2}{|c|}{ Ocorrência dos indicadores do nível de Reação } \\
\cline { 2 - 3 } & $M 1$ & $M 2$ \\
\hline Satisfação do professor quanto à vivência com os pares durante a formação. & 0 & 1 \\
\hline Satisfação do professor quanto à infraestrutura da instituição onde a formação foi realizada. & 0 & 1 \\
\hline Satisfação do professor quanto à atuação dos docentes formadores. & 3 & 3 \\
\hline
\end{tabular}

onde a formação foi realizada. Quanto ao primeiro indicador, foi verificado na colocação de $\mathrm{P} 2$, ao agradecer aos colegas de Curso pelos momentos de aprendizagem compartilhados (excerto 1). Já o segundo foi observado quando $\mathrm{P} 2$ agradeceu à USP pela infraestrutura disponibilizada à realização do curso (excerto 2).

1: Aos colegas do curso pelas oportunidades de aprendizagem e trocas de experiências. (P2)

2: À Universidade de São Paulo pela oportunidade e infraestrutura durante as atividades realizadas. (P2)

$\mathrm{O}$ indicador Satisfação do professor quanto à atuação dos docentes formadores foi verificado quando os professores agradeceram aos docentes do Curso pelo conhecimento compartilhado durante as disciplinas e também no processo de orientação para a elaboração da monografia, conforme pode ser observado, respectivamente, nos excertos 3 e 4 .

3: Aos professores que fizeram parte desse curso através das atividades desenvolvidas. (P2)

4: À minha orientadora, ..., pelo suporte, pelas suas correções e incentivo. (P1)

Dado os achados nesse nível de avaliação, considera-se que houve uma reação positiva por parte dos professores de química quanto ao Curso. A satisfação perpassou diferentes aspectos, a começar pela infraestrutura do CDCC, reconhecida como de excelência, ${ }^{7}$ contando não somente com salas para o oferecimento das aulas, mas também com exposições de diferentes áreas do conhecimento, biblioteca, laboratório de química e espaço maker. Os professores também se mostraram satisfeitos com o corpo docente e com a vivência com seus pares. Os participantes do Curso eram professores de diferentes cidades e de distintas áreas do conhecimento, diversidade essa que teve potencial de contribuir para uma troca frutífera de aprendizagem e experiências docentes.

Os resultados sinalizam, portanto, a adequação do Curso no que concerne a proporcionar uma estrutura física e ambiente de convivência harmonioso aos professores. Tais resultados são fundamentais para o sucesso da formação, visto que reações negativas e de insatisfação com o contexto da formação tendem a reduzir as possibilidades de aprendizagem dos participantes, bem como em transpor o conhecimento adquirido em seu ambiente de trabalho. ${ }^{10}$

\section{Nível 2: Aprendizagem}

Os indicadores do nível de aprendizagem foram observados, em quase sua totalidade, nas duas monografias (Quadro 4), em 92 UA na M1 e 90 UA na M2. As UA contempladas neste nível foram 
Quadro 4. Quantidade de UA das monografias dos professores de química relacionadas ao nível 2

\begin{tabular}{|l|c|c|}
\hline \multirow{2}{*}{} & Ocorrência dos indicadores do nível de Aprendizagem \\
\cline { 2 - 3 } & \multicolumn{1}{|c|}{$M 1$} & $M 2$ \\
\hline $\begin{array}{l}\text { Habilidade do professor em relacionar conteúdos teóricos abordados na formação a planejamento } \\
\text { de práticas docentes. }\end{array}$ & 3 & 14 \\
\hline Habilidade do professor em utilizar instrumentos de coleta de dados da prática docente. & 0 & 7 \\
\hline Habilidade do professor em tratar os dados resultantes da prática docente. & 9 & 6 \\
\hline $\begin{array}{l}\text { Habilidade do professor em analisar e/ou discutir os resultados da prática docente com base em } \\
\text { conteúdos teóricos. }\end{array}$ & 57 & 48 \\
\hline Habilidade do professor em concluir sobre os resultados provenientes da prática docente. & 23 & 15 \\
\hline
\end{tabular}

localizadas em diferentes seções, a saber: Resumo, Objetivos, Metodologia, Resultados e Discussão e Considerações Finais. A dispersão dos indicadores era esperada, visto que eles possuem uma aproximação com o processo de construção do conhecimento científico, envolvendo planejamento da pesquisa, implementação, análise dos resultados e conclusão do trabalho, os quais, quando descritos em uma monografia, ocupam praticamente toda sua extensão.

Considerando a quantidade de UA classificada em cada indicador, tem-se que Habilidade do professor em analisar elou discutir os resultados da prática docente com base em conteúdos teóricos apresentou maior ocorrência e foi identificado exclusivamente na seção de Resultados. O único indicador não observado nas duas monografias foi Habilidade do professor em utilizar instrumentos de coleta de dados da prática docente. Ponderamos que o fato de o referido indicador não ter sido observado na $\mathrm{M} 1$, não significa que P1 não procedeu a coleta de dados. De fato, na M1 há UA enquadradas no indicador referente ao tratamento dos dados, e isso só é possível quando há a correspondente coleta. Nesse caso, especula-se que a descrição da etapa de coleta de dados foi suprimida na redação do $\mathrm{P} 1$.

$\mathrm{O}$ indicador Habilidade do professor em relacionar conteúdos teóricos abordados na formação a planejamento de práticas docentes é constituído por colocações em que estes apontam como abordaram conteúdos em suas aulas, pautados em elementos teóricos discutidos na formação. Como exemplo, tem-se a colocação do P1 (excerto 5), na qual revela que usou blogs para favorecer a promoção da argumentação; e do P2 (excerto 6), que indica o uso de atividade experimental com abordagem investigativa em suas aulas.

5: Este trabalho tem como principal objetivo desenvolver e estimular a prática argumentativa dos alunos e a compreensão de conceitos científicos, por meio de uma intervenção didática baseada no uso dos blogs. (P1)

6: Para desenvolver essa pesquisa, foi necessário traçar um percurso para realizar o desenvolvimento de uma experimentação investigativa. $(\mathrm{P} 2)$

O indicador Habilidade do professor em utilizar instrumentos de coleta de dados da prática docente está exemplificado no excerto 7. Nele observa-se o emprego de questionário por parte do P2 para obter os dados referentes aos conhecimentos prévios dos alunos, os quais foram usados na análise da sua prática docente. Já o indicador Habilidade do professor em tratar os dados resultantes da prática docente foi observado em colocações nas quais $\mathrm{P} 2$ expressa como tratou os dados coletados (excerto 8), e em P1 como lançou mão de referenciais teóricos específicos da área para análise dos dados (excerto 9).

7: Inicialmente os alunos responderam a um questionário que permitiu averiguar seus conhecimentos prévios referentes às transformações dos estados físicos da água e o processo da chuva. (P2)

8: Os dados coletados foram analisados utilizando-se o critério de priorização, cuja metodologia envolve os itens mais relacionados ou o grau de importância sendo categorizados e agrupados itens relacionados à mesma questão ou etapa. (P2) 9: A estrutura dos argumentos apresentados nos blogs foi analisada de acordo com o Modelo de Toulmin (2001) e com o Modelo de Análise de Argumentação Aplicável a Processos de Resolução de Questões Socio-científicas (SÁ, 2010), descritos sucintamente no tópico a seguir. (P1)

$\mathrm{O}$ indicador Habilidade do professor em analisar elou discutir os resultados da prática docente com base em conteúdos teóricos foi identificado em situações nas quais estes procederam a análise e/ou discussão dos dados. O movimento ocorreu em duas perspectivas: na primeira, os professores discutiram o tipo e complexidade de conceitos apresentados pelos alunos (excerto 10); na segunda, valeram-se de referenciais teóricos adotados na área de Educação para analisar seus resultados de sala de aula. Tal movimento pode ser observado no excerto 11, em que P1 faz uso do Modelo de Toulmin, ${ }^{11}$ referencial voltado à análise estrutural dos argumentos científicos, para analisar seus dados.

10: Uma análise das respostas dos alunos considerando os exemplos de locais onde são encontrados os diferentes estados físicos da água (Quadro 5), mostram "o gelo" como o mais citado no estado sólido, ou seja, por metade dos participantes, o gelo é a situação que os alunos mais encontram no cotidiano, principalmente por morarem em um pais onde as temperaturas dificilmente atingem temperaturas abaixo de $0{ }^{\circ} \mathrm{C}$. (P2)

11: Dos argumentos postados nesse blog, podemos observar que o argumento da aluna Tatiana contempla os principais elementos do Modelo de Toulmin (2001), dado, justificativa e conclusão e suas seis justificativas estão acompanhadas por backing. (P1)

O último indicador desse nível Habilidade do professor em concluir sobre os resultados provenientes da prática docente corresponde a uma síntese da análise das suas ações nas aulas de química, após participação na formação. Obteve-se, para esse indicador, sínteses de três naturezas: a primeira envolve a retomada dos resultados, com apresentação de direcionamento às conclusões, como pode ser verificado no excerto 12 . Nele, o P1 faz uma retomada de qual foi a natureza dos argumentos apresentados pelos alunos e traz uma justificativa para a ausência de alguns elementos.

12: Todos os quatro blogs que foram analisados tinham pelo menos um comentário que contemplava a argumentação, de 
acordo com o Modelo de Toulmin (2001), e cabe destacar que os principais elementos (dado, justificativa e conclusão) estão presentes nos argumentos, sendo que grande parte das justificativas estão acompanhadas por backings, porém nenhum dos argumentos apresentou refutação e qualificador modal, que pode ser atribuído à falta de conhecimento por parte dos alunos sobre a estrutura de um bom argumento. (P1)

O segundo tipo de síntese envolve críticas do professor quanto a aspectos de sua prática docente, como verificado no excerto 13 . Nele consta a colocação do P2 com indicativo de conclusão sobre a escolha equivocada que adotou em usar simulação de fenômenos naturais na sua aula, com respectivas justificativas para tanto.

13: Durante a aplicação da sequência didática, pode-se verificar que a simulação de um fenômeno natural não foi a melhor escolha de atividade para ser desenvolvida, principalmente por se tratar da primeira vez que esta metodologia estava sendo utilizada para trabalhar um tema de Ciências e também pela falta de vivência dos alunos em relação às aulas experimentais. (P2)

O último tipo de síntese abarca reflexões dos professores quanto às implicações do seu trabalho, como pode ser verificado no excerto 14. No trecho em questão, o P1 aponta que, embora a atividade que desenvolveu em sua aula tenha sido voltada ao ensino de química, a mesma tem potencial para ser implementada em outras áreas do conhecimento.

14: Por fim, embora a proposta tenha se concretizado na disciplina de Química, ela pode ser aplicada com temas multidisciplinares e trabalhar várias disciplinas ao mesmo tempo, só é necessário a escolha de temas que sejam favoráveis às discussões e que despertem o interesse do aluno, também é necessária a participação dos professores como mediadores da atividade. (P1)

Tendo em conta os resultados desse nível, considera-se que a formação favoreceu a aprendizagem por parte dos professores de química, abarcando diferentes elementos que embasam uma prática docente em uma perspectiva reflexiva. ${ }^{12} \mathrm{~A}$ começar pela aprendizagem em planejar atividades de ensino com base em elementos teóricos da área de Educação. Esse processo foi verificado quando do uso de blogs nas aulas de química para promover um ambiente argumentativo e do emprego de atividades experimentais investigativas no ensino de conceitos químicos. Ademais, a análise das monografias evidencia que os professores colocaram as atividades planejadas em funcionamento nas suas aulas, coletaram dados delas resultantes, por meio de instrumentos específicos a tal fim, analisaram e discutiram os dados e trouxeram à baila conclusões de seu trabalho. Elas permearam sínteses dos resultados dos alunos, reflexões sobre aspectos da prática docente que poderiam ter sido desenvolvidos de maneira distinta e implicações da pesquisa para a literatura da área. Em suma, é possível afirmar que a contribuição da formação está associada ao atendimento da necessidade, praticamente consensual, "de se formar professores que reflitam sobre a sua própria prática, pois a reflexão será um instrumento de desenvolvimento do pensamento, da ação e de desenvolvimento profissional. O professor passa a ser visto como sujeito que constrói seus conhecimentos profissionais a partir de sua reflexão, experiência e da investigação da sua própria ação" (p. 120). ${ }^{12}$

Conhecidos esses resultados reputamos que os indicadores apresentados neste nível se mostraram robustos para a avaliação do nível de aprendizagem em cursos de formação continuada de professores, tornando viável esquadrinhar "informações que comprovem se os participantes melhoraram ou transformaram seus conhecimentos em habilidades ou atitudes pela qualificação oferecida" (p. 505). ${ }^{13}$

\section{Nível 3: Comportamento}

Todos os indicadores do nível comportamento foram localizados nas duas monografias, em 40 UA na M1 e em 38 UA na M2 (Quadro 5). Essas UA foram observadas, em sua maioria, nas seções de Metodologia e Resultados e Discussão.

$\mathrm{O}$ indicador Implementação por parte do professor de práticas docentes pautadas em elementos da formação foi o de maior frequência, sendo favorecido na seção de Metodologia, uma vez que abarca ações adotadas pelos professores para o desenvolvimento das aulas de química, ou seja, envolve a descrição das atividades que realizaram, o que tende a ser apresentado em uma monografia na referida seção. Os excertos 15 e 16 exemplificam tais ações.

15: A elaboração da atividade para criar os blogs foi proposta para ser realizada em grupos, onde cada grupo, além de criar o blog, teve que argumentar sobre temas sociocientíficos relacionados à Química. (P1)

16: Para responder à questão problema, os alunos foram divididos por afinidade de modo a formar quatro grupos (dois grupos com três integrantes e dois grupos com quatro integrantes), conforme mostrado no Quadro 3. (P2)

O indicador Adaptação por parte do professor do planejamento inicial de práticas docentes pautadas em elementos da formação também versa sobre ações implementadas em sala de aula, porém possui um caráter de exceção, por tratar especificamente daquelas que exigiram adaptações ao planejamento inicial. Logo, como era esperado, a sua recorrência é sensivelmente menor e a expectativa é que tais eventos sejam relatados na seção de Resultados e Discussão. No excerto 17 observa-se que P2 descreve um episódio desse tipo, em razão de questões organizacionais da escola.

17: A professora tinha como objetivo retomar a questão problema para que os alunos pudessem, a partir da realização de toda a sequência didática proposta, elaborar um texto que viesse responder a questão "Como acontece o processo da chuva?". Infelizmente, em função dos compromissos que sugiram na escola, esta atividade não pode ser realizada. (P2)

Quadro 5. Quantidade de UA das monografias dos professores de química relacionadas ao nível 3

\begin{tabular}{|l|c|c|}
\hline & \multicolumn{2}{c|}{ Ocorrência dos indicadores do nível de Comportamento } \\
\hline & $M 2$ & $M 1$ \\
\hline Implementação por parte do professor de práticas docentes pautadas em elementos da formação. & 36 \\
\hline $\begin{array}{l}\text { Adaptação por parte do professor do planejamento inicial de práticas docentes pautadas em } \\
\text { elementos da formação. }\end{array}$ & 35 \\
\hline
\end{tabular}


Os resultados alcançados no nível comportamento revelaram que os professores de química, ao voltarem as suas escolas, geraram ações docentes com base no que aprenderam durante a formação, incluindo a implementação de trabalhos em grupo, o uso de tecnologias de informação e comunicação e de textos de divulgação científica, o fomento a aulas argumentativas e ao ensino por investigação. Para Kirkpatrick e Kirkpatrick, ${ }^{14}$ esse nível é fundamental, com os indicadores remetendo à ocasião em que o participante volta ao seu ambiente de trabalho e busca melhorá-lo/modificá-lo, ou seja, aplica o que aprendeu na formação. Embora existam somente dois indicadores no nível comportamento do QAFP, eles se mostraram suficientes para a tessitura de considerações sobre ocasião tão relevante.

\section{Nível 4: Resultados}

Os indicadores deste nível foram localizados, considerando as duas monografias. As UA foram quase integralmente observadas na seção Resultados e Discussão, sendo 75 UA para M1 e 45 UA em M2 (Quadro 6). Esse resultado é compreensível, visto que os indicadores abordam justamente os resultados obtidos pelos professores ao desenvolverem suas aulas de química pautados em elementos da formação.

Com relação à ocorrência de cada indicador, tem-se que Conhecimentos e habilidades adquiridos pelos estudantes a partir da prática do professor compreendeu praticamente o total de UA desse nível. Isso pode ser justificado uma vez que o foco da análise dos professores na escrita das monografias estava na indicação da potencialidade das ações empregadas à aprendizagem dos alunos. Em contraponto, o indicador Impacto da performance do professor no ambiente escolar após participar da formação tende a ser revelado somente em espaços destinados à apresentação de uma autoavaliação sobre a prática docente, o que não é usual no contexto da escrita de uma monografia.

$\mathrm{O}$ indicador Conhecimentos e habilidades adquiridos pelos estudantes a partir da prática do professor foi identificado em situações nas quais ele atesta o conhecimento conceitual adquirido pelos estudantes ou aponta o desenvolvimento de suas habilidades, como argumentar, manusear aparatos experimentais e elaborar hipóteses. Exemplos podem ser observados, respectivamente, no excerto 18, no qual o P2 explicita conceitos aprendidos pelos alunos; e no excerto 19 , em que há indicação por P1 sobre a qualidade do argumento de uma aluna.

18: Alguns alunos, além de indicar as situações onde encontramos os diferentes estados físicos da água, apresentaram situações onde ocorrem mudanças de estado físico. (P2)

19: Dos argumentos postados nesse blog, podemos observar que o argumento da aluna Tatiana contempla os principais elementos do Modelo de Toulmin (2001), dado, justificativa e conclusão e suas seis justificativas estão acompanhadas por backing. (P1)

Com relação ao indicador Impacto da performance do professor no ambiente escolar após participar da formação, ele foi expresso quando da afirmação do professor de que a atividade desenvolvida contribuiu com suas ações pedagógicas, o que foi verificado apenas na M2, conforme exemplificado no excerto 20.

20: Através do curso de especialização em ensino de Ciências, realizado pelo CDCC- Centro de Divulgação Cultural e Científica de São Carlos, tive a oportunidade em conhecer "novas" metodologias de ensino e diversificar minha prática. (P2).

A análise desse nível revela que a implementação, por parte dos professores de química, de ações pautadas em elementos da formação em suas aulas, com promoção da aprendizagem dos alunos foi alcançada. Na presente investigação, o alcance desta constatação foi viável devido à natureza do conjunto de dados analisados, formado pelas monografias, nas quais constam o relato propriamente dito das ações didáticas desencadeadas na Educação Básica. No entanto, existe um consenso na literatura ${ }^{10}$ sobre as dificuldades enfrentadas para identificação desse nível, visto que mecanismos para que sejam conhecidas as atividades realizadas pelos professores no ambiente de trabalho, com base nos conhecimentos adquiridos na formação, não são facilmente colocados em funcionamento.

Os apontamentos presentes nessa seção revelam o potencial dos centros de ciências no desenvolvimento profissional de professores de química, o que vem a corroborar os trabalhos de Silva, ${ }^{2}$ e de Silva e Freitas, ${ }^{15}$ os quais revelaram que professores desse componente curricular, ao participarem de uma formação continuada sobre atividade experimental em um centro de ciências, consideraram que suas necessidades formativas foram atendidas, perceberam mudanças em sua prática profissional quanto ao uso de atividades de tal natureza e que a seriedade da instituição fomentou a parceria entre os professores universitários e os da Educação Básica.

\section{CONSIDERAÇÕES FINAIS}

Neste trabalho procedemos a construção do QAFP e o aplicamos na análise de monografias de química, o que permitiu concluir que os professores dessa área, ao participarem do Curso de Especialização em Metodologia do Ensino de Ciências Naturais: ficaram satisfeitos com a formação (nível 1), destacando o seu contentamento com a infraestrutura do CDCC, com a atuação do corpo docente do Curso e com a vivência com demais professores participantes da formação; aprenderam conceitos abordados na formação (nível 2), conforme verificado no planejamento e análise das atividades de ensino em química que idealizaram; implementaram em suas aulas temas abordados na formação (nível 3), como tecnologia da informação e comunicação, argumentação, ensino por investigação, atividades experimentais e textos de divulgação científica; obtiveram resultados positivos de suas ações docentes (nível 4), revelados nos indícios da aprendizagem dos alunos e no impacto da formação na prática docente.

O QAFP apresenta-se, portanto, como uma ferramenta que pode evidenciar as contribuições dos cursos de formação à prática do professor, sendo apontadas, a seguir, algumas das suas potencialidades e limitações. A começar pelas potencialidades,

Quadro 6. Quantidade de UA das monografias dos professores de química relacionadas ao nível 4

\begin{tabular}{|l|c|c|}
\hline \multirow{2}{*}{} & \multicolumn{2}{|c|}{ Ocorrência dos indicadores do nível de Resultados } \\
\cline { 2 - 3 } & \multicolumn{2}{|c|}{$M 1$} \\
\hline Conhecimentos e habilidades adquiridos pelos estudantes a partir da prática do professor. & 75 & 44 \\
\hline Impacto da performance do professor no ambiente escolar após participar da formação. & 0 & 1 \\
\hline
\end{tabular}


destaca-se fortemente o fato de ter sido moldada de maneira a permitir a análise de monografias de conclusão de cursos de especialização lato sensu. Nessa perspectiva, a ferramenta encontra amplo campo de aplicação, uma vez que estes cursos são recorrentemente frequentados por professores. Ademais, até onde vai o nosso conhecimento, é ferramenta única com esse viés no ensino de ciências, considerando o contexto nacional. Colocar a monografia no centro das atenções quando são avaliadas ações formativas é relevante, pois a sua elaboração, segundo Chamon, ${ }^{16}$ é um momento que costuma ser reconhecido pelos professores como de aprendizado, ainda que permeado por dificuldades.

Uma potencialidade da ferramenta que também merece ser apontada é a sua versatilidade, no que diz respeito a ser viável que os indicadores que a constituem norteiem o trabalho dos formadores de professores, ao elaborarem suas aulas e realizarem a orientação das monografias. Além disso, os indicadores também podem pautar a construção de questionários com perguntas sobre os níveis aos quais se associam, tendo em vista a avaliação da formação por parte dos cursistas.

Quanto às limitações da ferramenta, um nível e um indicador foram pouco contemplados nas monografias analisadas, o que sugere uma fragilidade da mesma em identificá-los. O primeiro é relacionado à reação do professor quanto á formação (nível 1), enquanto o segundo trata do impacto da atuação do professor no contexto escolar (terceiro indicador do nível 4). A fragilidade é resultante, para o caso do nível 1, do fato de excertos relacionados à reação possuírem localização restrita à seção de Agradecimentos da monografia, que possui uma extensão reduzida no texto. Para o caso do indicador do nível 4, ele é mais claramente evidenciado em excertos relacionados à apresentação de uma autoavaliação sobre a prática docente, o que é pouco usual no contexto da escrita de uma monografia. Assim sendo, é enriquecedora a associação do uso da ferramenta, quando possível, à análise de textos produzidos pelos professores ou de respostas oferecidas a entrevistas baseadas em questionamentos capazes de elucidar os aspectos indicados.

Uma segunda limitação da ferramenta é o fato de a pertinência da sua utilização estar atrelada à natureza da monografia produzida. De fato, monografias de cunho teórico, como revisões bibliográficas, não são passíveis de análise via QAFP, pois, para tanto, é essencial que os instrumentos de coleta de dados adotados pelo professor permitam a obtenção de informações sobre o processo de implementação de atividade relacionada à formação, bem como dos resultados dela derivados.

Por fim, aos interessados no uso da ferramenta, chamamos a atenção para a maior frequência de determinados níveis em seções específicas das monografias, a saber: nível de reação (nível 1), em sua maioria, indicadores observados na seção de Agradecimentos; nível de aprendizagem (nível 2), indicadores distribuídos nas seções Resumo, Objetivos, Metodologia, Resultados e Discussão e Considerações Finais; nível de comportamento (nível 3), indicadores observados, em especial, na seção de Metodologia; nível de resultados (nível 4), indicadores verificados quase que exclusivamente na seção de Resultados.

\section{AGRADECIMENTOS}

O presente trabalho foi realizado com apoio do Conselho Nacional de Desenvolvimento Científico e Tecnológico (CNPq), Processo 304974/2020-0.

\section{REFERÊNCIAS}

1. Silva, O. B.; Queiroz, S. L.; Alexandria: Revista de Educação em Ciência e Tecnologia 2017, 10, 271.

2. Silva, V. F.; Tese de Doutorado, Universidade Estadual Paulista, Brasil, 2013.

3. Tempesta, A. M.; Gomes, L. C.; Investigações em Ensino de Ciências 2017, 22, 78.

4. André, M.; Educação Unisinos 2015, 19, 34.

5. Opletalová, A.; Journal of Education and Training Studies 2018, 6, 164.

6. Kirkpatrick, D. L.; Kirkpatrick, J. D.; Implementing the four levels; Berrett-Koehler Publishers: San Francisco, 2007.

7. https://sites.usp.br/cdcc/wp-content/uploads/sites/512/2019/06/2016Memorias_do_CDCC.pdf, acessada em maio 2021.

8. Possenti, S.; Perspectiva 2002, 20, 105.

9. Jabareen, Y.; International Journal of Qualitative Method 2009, 8, 49.

10. Baracas, A. R. C.; Dissertação de Mestrado, Universidade de Lisboa, Portugal, 2017.

11. Toulmin, S. E.; The uses of argument, Cambridge University Press: New York, 2003.

12. Vidrik. E. C. F.; Investigación en la Escuela 2020, 101, 118.

13. Silva, N. P.; Francisco, A, C.; Hatakeyama, K.; Silva, M. C. G.; Emancipação 2010, 10, 501.

14. Kirkpatrick, J. D.; Kirkpatrick, W. K.; Kirkpatrick's four levels of training evaluation, ATD Press: Alexandria, 2016.

15. Silva, V. F.; Freitas, M. F.; Instrumento: Revista em estudo e pesquisa em educação 2016, 18, 99.

16. Chamon, E. M. Q. O.; Psicologia da Educação 2007, 25, 157. 